2016 Modular and Offsite Construction (MOC) Summit

Edmonton, Alberta, Canada, September 29 - October 01, 2016

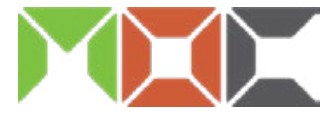

\title{
Analysis framework of off-site manufacturing solutions : case study of a powerhouse complex
}

\author{
Pierre COLLOT ${ }^{1,2 *}$, Daniel FORGUES ${ }^{1,2}$ and Louis RIVEST $T^{2,3} *$ \\ ${ }^{1}$ Département du Génie de la Construction, École de Technologie Supérieure (ETS) \\ ${ }^{2}$ Groupe de recherche en intégration et développement durable en environnement bâti \\ ${ }^{3}$ Département Génie de la Production Automatisée, (ETS) \\ *Corresponding author's e-mail: pierre.collot.1@ens.etsmtl.ca
}

\begin{abstract}
The quest for improved productivity and optimized construction costs are continuously challenging the industry. The experience gained from the manufacturing industry showed that offsite manufacturing appears to be a promising alternative to the classic way of building a powerhouse complex. However, singularity of projects, sizes of powerhouse complexes and multiplicity of stakeholders greatly impact the integration of such practices. To fully assess the benefits of off-site manufacturing, and to guarantee its integration within the project, it is essential to understand the issues in order to characterize benefits related to construction projects in remote areas. In this paper, the research explores off-site manufacturing integration in the industrial context of a major Canadian utility company. One of the goals is to reduce the duration and costs of construction of a future powerhouse complex project through the use of off-site fabrication. The objective of this research is to maximize these benefits of off-site fabrication through the identification of the best available strategies. To do this, a strategic analysis is conducted to evaluate off-site fabrication impact over current processes. Then, an economic analysis estimates the benefits of potential decisions made during the engineering phase. This research contributes to the construction industry by proposing an analysis framework for the identification of off-site manufacturing solutions in the context of a powerhouse complex project.
\end{abstract}

\section{KEYWORDS}

Off-site manufacturing; Construction; Process; Powerhouse complex; Benefits; Economic analysis

\section{INTRODUCTION}

Productivity research is one of the major challenges in the various sectors of the industry. The optimization of projects schedules and implementation costs represent major issues for the construction sector. To obtain the most promising benefits, the construction stakeholders need to reconsider theirs working methods drawing on best practices from other industries. In the report Rethinking Construction, Egan (1998) identifies that relationships within the supply chain, standardization and off-site manufacturing (OSM) play major roles in improving the design and construction process. 
In contrast to residential construction, the state of art for OSM practices for industrial projects, like powerhouse complex, is not well documented. However, most of the concepts are similars and can be adopted (Gibb,1999). The potential benefits associated with OSM to reduce construction costs, lower duration timelines, improve the quality of the work and adopt an approach in line with sustainable development are among the reasons why owners want to integrate OSM in their projects (Javanifard et al., 2013). Moreover, the manufacturing expertise could help to optimize the construction process, especially with the Lean know-how. Indeed, on the whole activities performed, $62 \%$ of the factory workers bring added value to the project against $10 \%$ for the worker on a construction site (Teicholz, 2013). However, the use of OSM also generates constraints that require reassessment of traditional construction processes. Some approaches are too expensive to justify the use of OSM in a project (Gibb, 1999). According to Blismas and al. (2005), the main constraint in using OSM is that you need to freeze the design very early in the project process. The impacts of change requests to the design are more pronounced with OSM, due to the lack of standardization of communication and coordination process between the stakeholders (Gibb, 1999). But the emergence of new project management practices and IT applications, for example with the Building Information Modeling, suggests opportunities to remedy this lack of coordination in the construction industry and to improve the productivity, especially during the design phase (Eastman, 2008). These factors are key elements in the success of a OSM integration. The project process must push stakeholders to focus their efforts upstream in order to integrate all the requirements during design and identify the best benefits (Demers, 2013). The experience gained on previous projects then proves itself essential to avoid repeating the same problems with the integration of OSM and thus maximize benefits.

Based on the experience in similar projects, this case study presents an approach to identifying the most promising OSM practices to reduce time and construction costs, while taking into account the experience gained by the company in previous projects.

\section{RESEARCH METHODS}

The purpose of this research is to maximize OSM benefits during powerhouse complex construction. The case study takes place within the engineering department who is responsible for the complex's design and for providing technical support to contractors after the bidding. OSM appears as one of the many existing solutions to reduce construction cost of company's projects. The studied complex has the distinction of being the last entity in a group of powerhouse projects. Due to the similarities of previous projects, analogies are made to establish recommendations for the current case study.

The research method, as shown in Figure 1, is divided into three phases.

- In the preliminary study phase, the current project realization processes are mapped and the company's OSM practices inventoried.

- The analysis phase is divided into two parts. The first part determines OSM experience gained by the different engineering sectors over the past projects. In the second part, the potential benefits of OSM practices for the project studied are identified.

- An interpretation phase based on the above analyzes completes the process. The most promising OSM practices are then recommended, in the context of the project. 


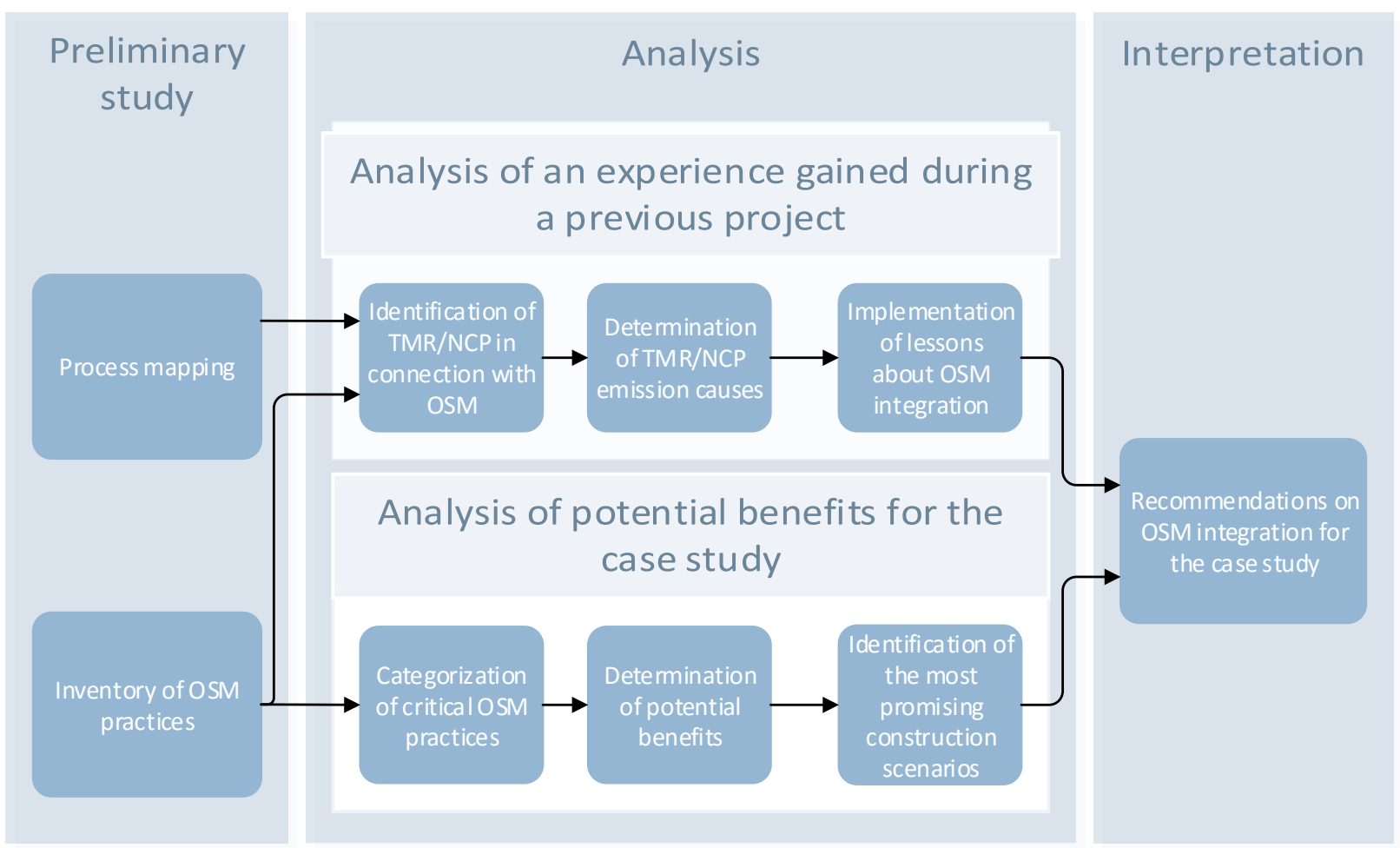

Figure 1 - Stages of research methodology

First, the preliminary study establishes an overview of the current situation. From the point of view of the inner workings of the company, process mapping identifies activities, required deliverables and major decisions made during a project. The goal is to identify the stakeholders and the processes that influence OSM. From the point of view of the company's expertise in terms of OSM, an inventory of potentially applicable practices is established. This work is based on previous project summary reports and current ongoing studies in the engineering department. Then, the analysis phase presents an approach to identify OSM practices with the most compelling potential benefits, while relying on the experience gained in previous projects. Due to the similarity of the powerhouse complex built on the site, there is certain repeatability between projects. Feedback on lessons learned allows us to optimize construction methods and improve benefits generated. In this context of this study, two analyzes are performed together: one to take stock of the company's experience in terms of OSM on a similar project, the other identifying the potential benefits of OSM on the considered case study.

The first study is based on the interaction between the supply chain and prime contractor in factory production equipment and onsite installation, especially on the change requests that affect the initial project design. It identifies the successes and potential improvement areas by the integration of OSM. Two types of interactions are thus addressed: Technical Modification Requests (TMR) and Non-Compliance Product (NCP). TMR allows initiating change requests, innovation and technical fixes after the tendering phase. Most of the time, TMR are considered as an opportunity of improvement for the company during the manufacturing and construction phases. NCP identifies situations that do not comply with the requirements specified in the contract during the design, manufacture and installation phases. NCP can eventually lead to TMR. The first step is to 
identify the TMR/NCP related to OSM. An Excel program allows exporting and sorting of all requests in the company's database. The second step is the determination of emission causes of TMR/NCP in connection with OSM. A representative sample of TMR/NCP is selected to allow categorizing of these emission causes. Thus, a review of the company's experience is established based on the identification of best OSM practices controlled and estimating the impact of change requests on a project similar to our case study.

The second study proposes an approach to estimate the potential benefits of OSM on a project. In powerhouse complex projects, the economic gains associated by the advancement of the commissioning date of production groups are considerable. It explores ways to reduce the timeline with OSM, while considering the direct and indirect costs related to the integration of such practices. The first step is to determine the critical path of the project from the preliminary master schedule. Thus, based on the inventory established during the previous phase, a classification of OSM practices which have a direct impact on the schedule is made. The second step is to assess the potential benefits of these practices on the critical path. First from a local perspective, the estimated installation time, the direct and indirect costs are established for each OSM "critical" practice comparing to traditional construction methods. From this point, the overall impact of the OSM integration project schedule is made, such as the impact on the commissioning date and project costs according to different construction scenarios. Thus, OSM practices with the most promising potential benefits are identified.

Finally, the results interpretation phase is the junction between the two previous analyses. An assessment is established, based on the experience gained by the company in the use of OSM and practices offering the best benefits for the project. Recommendations are made to the company to identify the best benefits. These are based, in particular, on the causes of recurrent changes requests in previous projects, current processes related to OSM and its integration into existing projects.

\section{PRELIMINARY RESULTS AND DISCUSSION}

During the preliminary study phase, a mapping of internal company processes is performed to understand the roles and responsibilities of the units during the different phases of a new powerhouse complex project. This work establishes an overview of the activities and deliverables required from the preliminary design stage to the delivery to the operator. Particular attention is paid to the process in connection with OSM during the project, more specifically in the design of equipment and technical support in the factory and on site. For each work-packages established during the preliminary design phase, the engineering process is based on four iterations for different degrees of completion of the design. Each iteration follows the same sequence, based on the "Top-Down" approach: studies related to the surrounding environment of the plant (geotechnical, environmental, soil mechanics) are made first, then comes the envelope engineering (concrete, structure, architecture) and finally studies on powerhouse equipment (power generators, auxiliary mechanical, electrical and control) are performed. A closer analysis of the OSM process will be carried out once the mapping has been validated by the company.

In order to understand the range of possibilities of OSM for the case study considered, an inventory of practices is completed by the design department. Based on the know-how from previous projects and technical innovations under development, 57 solutions are identified in six engineering 
divisions: civil (structure and architecture), electrical, auxiliary mechanical, ordering, heavy engineering and production groups. Table 1 summarizes the distribution of OSM practices between different areas of engineering. The solutions implemented in previous projects are named existing solutions and solutions potentially applicable to future projects are called solutions under development.

The analysis of the potential OSM benefits is based on the previously identified best practices. The purpose of this study is to evaluate the economic impact of OSM in the relevant project. According to context, the use of OSM tends to generate higher direct costs than traditional construction because of manufacturing and transport costs in addition to installation costs. However, OSM may allow a reduction of working time on the site, which implies a reduction of indirect costs (equipment capital cost, cost of labor, overhead construction). This can also be used to advance the powerhouse's commissioning date and improve the revenue for the owner. To perform the analysis of the benefits, inventoried OSM practices are categorized according to their level of criticality during the project. The first level corresponds to the practices on the project manager's critical path. The second level includes practices that would be on the critical path in the event of the reduction in installation time of a practical outcome in the first level. The third level covers all other inventoried practices. The distribution of OSM practices according to their level of criticality is presented in Table 1 . Thus, for the case study considered, $32 \%$ of OSM practices inventoried are found directly in the project's critical path and the number of practices located on the second level of criticality represents $42 \%$ of the inventory. Among the engineering divisions having activities with high levels of criticality, production group, manufacturing and installation leads with $90 \%$ of activities on the critical path. Then, civil and heavy engineering have respectively $50 \%$ and $37 \%$ of activities with a level of criticality. Furthermore, all practices corresponding to auxiliary mechanical and electrical equipment are critical to level 2, as are $57 \%$ of activities from ordering engineering. To estimate OSM's potential benefits, only activities on the project's critical path are taken into account for the remainder of the study. An evaluation of the differences in direct costs, indirect costs and construction time between conventional and OSM construction methods are performed for each of the 18 practices at criticality level 1 . This study is currently underway. This analysis concludes with a study of the various possible recommended scenarios. Hence, the gains from potential acceleration of the powerhouse commissioning date will be weighed against the direct and indirect variation costs compared to conventional methods. The most promising OSM practices within the case study will be identified and their benefits estimated.

Table 1 - Summary of OSM practices inventoried and their level of criticality in engineering

\begin{tabular}{|c|c|c|c|c|c|c|c|c|c|}
\hline & & Civil & Electric & $\begin{array}{l}\text { Auxiliary } \\
\text { mechanical }\end{array}$ & Ordering & $\begin{array}{c}\text { Heavy } \\
\text { engineering }\end{array}$ & $\begin{array}{l}\text { Production } \\
\text { groups }\end{array}$ & & \\
\hline \multirow{2}{*}{$\begin{array}{l}\text { Types of } \\
\text { solutions }\end{array}$} & Existing solutions & 10 & 9 & 7 & 5 & 7 & 6 & 44 & $77 \%$ \\
\hline & $\begin{array}{c}\text { Under development } \\
\text { solutions }\end{array}$ & 2 & 3 & 1 & 2 & 1 & 4 & 13 & $23 \%$ \\
\hline \multirow{3}{*}{$\begin{array}{l}\text { Level of } \\
\text { criticality }\end{array}$} & Critical level 1 & 6 & 0 & 0 & 0 & 3 & 9 & 18 & $32 \%$ \\
\hline & Critical level 2 & 0 & 12 & 7 & 4 & 0 & 1 & 24 & $43 \%$ \\
\hline & Critical level 3 & 6 & 0 & 0 & 3 & 5 & 0 & 14 & $25 \%$ \\
\hline
\end{tabular}




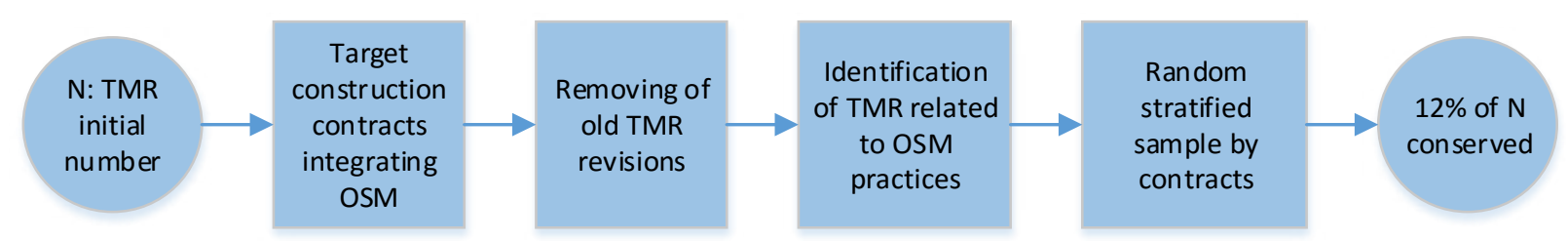

Figure 2 - Selection method of TMR and NCP in connection with OSM practices

The second analysis focuses on OSM experience from a previous project that is technically similar. Process mapping reveals the main interaction between contractors (manufacturer, contractor) and the work provider (the company) is during the technical support in the manufacturing or construction phases. Indeed, the project is administered using a Design-Bid-Build contract. The supply chain therefore has no influence in the complex's design. Once the contract is awarded, the contractor discusses the design and construction methods with the client. TMR and NCP are communication procedures for identifying on site abnormalities and making change requests during a project. This analysis examines the TMR and NCP for an OSM project similar to that of the case study. In order to extract information in connection with OSM practices from the company's internal database, a selection procedure is performed on TMR. This procedure is shown in Figure 2. The selection of construction contracts including the fabrication or installation of OSM practices allows us to reduce the TMR number of the project. Then, an Excel program removes old TMR revisions. After identifying the TMR in connection with OSM, sampling is performed to obtain a representative number of TMR to analyze. This is a random stratified sample based on construction contracts in order to meet the proportion of TMR between contracts. This drawing is based on Gauss's law which ensures an approximate 95\% accuracy level. The TMR sample retained represents $12 \%$ of the initial $\mathrm{N}$ number. Of the 19 selected construction contracts, the contract for the supply and installation of auxiliary mechanical and electrical equipment represents a major part of the final TMR sample. This figure is supported by the literature, since this type of equipment is a common source of interference in construction projects (Bernstein, 2011).

For each sampled TMR, a search is performed in the database to identify and categorize the causes of emissions during the project as follows:

- Revision of initial engineering: Necessary design resumption or construction methods decided in the tender documents.

- Onsite contingencies: Change requests to deal with events beyond the control of the prime contractor during the production, transport or installation.

- Coordination problem: Locations changes or equipment installation methods due to interference during onsite installation.

- Proposal of alternative methods: Use of an equivalent method during fabrication or installation phases by the manufacturer or contractor to the work provider.

- Transfer of activity: Amendment to add or remove an activity to the initial manufacturing or installation contract.

- Additional information: Additional information request to the prime contractor leading to TMR. This can be a specification of the contract documents or updated information due to a change in the upstream engineering. 
Once this TMR categorization phase is complete, a similar process will be carried out on the NCP. A report based on the experience gained with OSM can then be generated. Indeed, a report on lessons learned will be formulated based on six different engineering divisions. These results, from a previous project, will then be crossed with the level of criticality and the potential benefits of OSM practices. For example, identification of OSM practices with criticality level 1, frequently subject to interference problems will now be possible. Specific recommendations on engineering direction will then be made to identify OSM practices with the most promising potential benefits. In addition, a reorganization of the engineering process can be proposed based on the results obtained.

\section{CONCLUSIONS}

To allow full adoption of off-site manufacturing, various economic, technical, relational and organizational parameters would be taken into account in order to overcome the inherent constraints of the integration of this new construction approach. This research proposes an analytical framework for identifying the most relevant OSM practices to integrate into a powerhouse complex project, based both on experience gained on previous projects and an economic study. The specificity of this study lies in the fact that a series of similar projects have previously been conducted or are underway in similar working conditions. The main principles of the design and construction methods used can be transposed and optimized from one project to another. At this stage of the study, the OSM practices associated with civil engineering and power generation equipment has promising prospects for optimize construction schedules in order to advancing powerhouse commissioning dates and thus reducing the cost of the project.

The contribution of this research is to provide the construction industry an analytical framework for the identification of OSM solutions to maximize the benefits of a project, based on the experience gained in previous projects. This research proposes a new methodology to improve the benefits of OSM in reducing costs in powerhouse complex projects. The next stage of research will be to strengthen the validity of the results and the representativeness of the sampling by adopting a similar approach when other powerhouse projects are finalized. This approach will represent the evolution of OSM integration and perception of the potential benefits in various projects.

\section{ACKNOWLEDGEMENTS}

This study was funded through the Scholarship in Practical Environment program, a joint initiative of the Natural Sciences and Engineering Research Council and Engineering Research Canada (NSERC) and the Quebec Research Funds - Nature and Technology (FRQNT). We are also very grateful to the industrial partner for their support during this project and assistance to access data and information.

\section{REFERENCES}

Bernstein, Harvey. (2011). "Prefabrication and Modularization: Increasing Productivity in the Construction Industry". McGraw Hill Construction.

Blismas, Nick G., Martyn Pendlebury, Alistair Gibb and Christine Pasquire. 2005. " Constraints 
to theUse of Off-site Production on Construction Projects “. Architectural Engineering and Design Management, 1(3), 153-162.

Demers, Clément. (2013). “Gestion de projets: Leadership, collaboration et innovation “ Séminaires en gestion de projet de la construction. Montréal, QC,CA:

Eastman, Chuck, Paul Teicholz, Rafael Sacks and Kathleen Liston. (2008.) "BIM handbook : a guide to building information modeling for owners, managers, designers, engineers, and contractors". John Wiley \& Sons, Hoboken, N.J, USA.

Egan, Sir John. (1998). "Rethinking Construction: the Report of the Construction Task Force" Departement of trade and industry, London, UK.

Gibb, Alistair GF. (1999). "Off-site fabrication: prefabrication, pre-assembly and modularisation”. John Wiley \& Sons, New York, NY, USA.

Javanifard, Naomi, Debra Markert, Kristen Strobel, Jason Yap and Azari Rahman. (2013). "Modular prefabricated residential construction: constraints and opportunities". Seattle, WA, USA $90 \mathrm{p}$.

Teicholz, Paul. (2013). "Labor productivity declines in the construction industry: causes and remedies (another look)". 